\title{
Territorios y resistencias: configuraciones generacionales y procesos de politización en Argentina
}

Territories and resistances: generational configurations and processes of politicization in Argentina

Pablo Ariel Vommaro*

Instituto Gino Germani-Universidad de Buenos Aires-ConicET-Clacso, Argenitna ORCID: http://orcid.org/0000-0002-6957-0453 doi: http://dx.doi.org/10.28928/revistaiztapalapa/822017/atc4/arielvommarop

\section{Resumen}

Las juventudes se han convertido en activos protagonistas de los principales procesos de movilización en numerosos países de América Latina en los últimos años, signando la dinámica del conflicto social y las agendas públicas. El artículo se propone abordar los procesos de politización generacional desplegados en América Latina en los últimos años que expresan resistencias territorializadas y constituyen la dinámica de los procesos de disputas por lo público, conformando una dimensión fundamental en la dinámica del conflicto social y la emergencia de resistencias en la región. Palabras clave: juventudes, territorios, politización, resistencias, América Latina

\section{Abstract}

The youth have become major players in the main mobilization processes in numerous countries of Latin America in the last years, denoting the dinamics of social conflict and public agenda. This article proposes to approach the processes of generational politization deployed in Latin America in the last years and expresses territorialized resistances and constitute the dinamic of the processes that dispute the public space, forming a fundamental dimension in the dynamics of social conflict and the emergence of resistance in the region. Key words: Youth, territory, politicization, resistance, Latin America

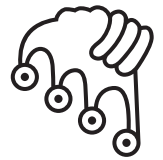

IZTAPALAPA

Agua sobre lajas

*pvommaro@gmail.com 
L as juventudes se han convertido en activos protagonistas de los principales procesos de movilización en numerosos países de América Latina en los últimos años. Imprimen su signo a la dinámica del conflicto social y a las agendas públicas. En efecto, organizados en diversas agrupaciones y colectivos despliegan resistencias innovadoras y prácticas disruptivas que muchas veces producen fugas, sustracciones y nomadismos respecto de las lógicas dominantes. Así, comprender los procesos de producción política generacionalmente configurados es una vía de ingreso para la interpretación de dinámicas políticas de resistencia más generales.

En este sentido, la construcción social del espacio llega a ser un aspecto central del proceso de politización configurado con base en la producción de territorios. En su dinámica se manifiestan resistencias cuya expresión en corporalidades y afectividades resitúa las relaciones entre lo privado y lo público. Emerge así lo público como el ámbito de lo común en disputa, más allá de los contornos estatales y avanzando hacia formas comunitarias situadas.

A partir de lo dicho, el objetivo de este artículo es abordar diversas experiencias de politización generacional presentes en la Argentina y en América Latina en los últimos años que expresan resistencias territorializadas y constituyen la dinámica de los procesos de disputas por el uso, apropiación y producción de lo público, y que conforman de ese modo una dimensión fundamental en la dinámica del conflicto social y la emergencia de resistencias en la región.

En un primer momento presentaremos las perspectivas y los puntos de partida desde los cuales abordamos los problemas referidos introduciendo el enfoque que nos permite hablar de procesos de politización territorial generacionalmente configurados. Luego, indagaremos en tres experiencias juveniles en la Argentina entre los años noventa y la actualidad. Por último, propondremos algunas reflexiones finales planteando interrogantes para seguir trabajando y pensado en el tema. 
El texto es producto de una sistematización de diversas investigaciones del autor y de los equipos que él mismo integra o coordina. ${ }^{1}$ La metodología utilizada es de carácter cualitativo, con base en entrevistas a profundidad realizadas a partir de ingresos etnográficos en el campo, análisis de documentos producidos por las organizaciones con las que se trabaja, artículos de prensa escrita y confrontación de bibliografía secundaria.

Las entrevistas se realizaron en diversos momentos a personas que pueden ser consideradas cuadros medios y que tuvieron una participación interpretada como relevante en los procesos que se abordan en cada caso, además de expresar una perspectiva generacional evaluada no solo a nivel etario.

Trabajamos desde la historia oral ${ }^{2}$ con entrevistas situadas que fueron parte y resultado de un abordaje etnográfico (Aguirre, 1995; Hammersley y Atkinson, 1994; Guber, 200I) que nos permitió un acercamiento a la vida cotidiana de las organizaciones sociales seleccionadas. De ese modo, además de producir descripciones densas o interpretaciones (Geertz, 1993), ${ }^{3}$ fue posible emprender un proceso reflexivo de selección de los entrevistados. Comenzamos por elegir los primeros entrevistados en el MDT de Solano y luego accedimos a las entrevistas de los protagonistas de las tomas y los asentamientos de 1981. Se realizaron 20 entrevistas hasta lograr la saturación (Bertaux, 2005; Kornblit, 2004) a partir de las técnicas de "bola de nieve" y "saltar el cerco" (Bertaux, 2005 y Guber, 200I). Así llegamos a otros informantes que no estaban ligados a los primeros. Esto nos permitió acceder a otras perspectivas y puntos de vista (Necoechea y Pozzi, 2008) que nos ayudaron a componer las interpretaciones que aquí exponemos.

Asimismo, el trabajo con documentos producidos por las organizaciones seleccionadas en este escrito y con artículos periodísticos acerca de cada una de las experiencias de politización y momentos históricos estudiados se realizó a partir de la triangulación (Kornblit, 2004) con los datos producidos a partir de las entrevistas. Esto también hizo posible complejizar y densificar nuestras interpretaciones.

1 Nos referimos particularmente al Equipo de Estudios de Políticas y Juventudes (EPoJu), del Instituto de Investigaciones Gino Germani de la Universidad de Buenos Aires, que el autor cocoordina, y al Grupo de Trabajo cLAcso sobre Juventudes y políticas, del cual el autor e integrante.

2 Para ampliar acerca de las perspectivas de la historia oral, véase, entre otros, a Joutard, 1986; Portelli, 1997, 2000; Bertaux, 2005 y Necoechea y Pozzi, 2008.

3 Para Geertz (1993) la descripción densa o interpretación reconoce los marcos de interpretación dentro de los cuales los actores clasifican el comportamiento y le atribuyen sentido. Este autor propone que el investigador debe aprehender las estructuras conceptuales con las que la gente actúa y hace inteligible su conducta y la de los demás (Geertz, 1993). 


\section{Juventudes, politizaciones, territorios}

Un primer punto de partida para abordar los estudios con juventudes es señalar su carácter plural, diverso y múltiple en la actualidad. Así, la pluralización del término juventud busca enfatizar las diversidades como marca de época de las juventudes. Como señalamos en otros trabajos (Vommaro, 2015), mientras muchos estudios conciben este rasgo en clave de fragmentación, nosotros lo pensamos como potencia y capacidad de las juventudes en la actualidad. Como veremos más adelante, estas diversidades pueden ser analizadas como marca generacional y posibilidad de construcción de lo común a partir de su reconocimiento, tensionando las relaciones entre diferencia e igualdad.

Las diversidades que caracterizan a las juventudes en la actualidad ${ }^{4}$ pueden vincularse también con el proceso de juvenilización de la vida y la sociedad que se despliega hace algunas décadas a nivel mundial. En efecto, muchos rasgos atribuidos a los jóvenes se han diseminado hoy por diversos grupos y esferas sociales no específicamente juveniles. ${ }^{5}$ Hoy el mundo es mucho más juvenil y más femenino que hace algunas décadas. Esto no quiere decir que haya más jóvenes -o más mujeres - que antes. No se trata de una cuestión demográfica, sino que llamamos la atención acerca de que atributos asignados a las juventudes como el dinamismo, la flexibilidad, lo festivo o la alegría son consagrados como atributos deseables y dominantes no tan solo para las personas consideradas jóvenes. Este cambio de mediana duración puede verse tanto en dimensiones políticas como culturales, en pautas de consumo, modos y estilos de vida, en la fuerza de trabajo, en las sexualidades o en las migraciones.

Este enfoque permite enfatizar la importancia de estudiar los procesos y modos de producción socio-estatal de las juventudes. Es decir, hablar hoy de juventudes explica y describe poco si no situamos nuestro análisis y enfatizamos las singularidades de las juventudes para, a partir de allí, identificar sus rasgos comunes. En efecto, la de juventudes es una noción producida desde diversos dispositivos entre los que destacamos: las políticas públicas (no solo las sectoriales, sino en un sentido amplio), los medios de comunicación y discursos públicos, el mercado y la

4 En otros trabajos abordamos las diversidades juveniles en relación con las desigualdades generacionales y trabajamos las tensiones entre diferencia e igualdad (Vommaro, 2015). Aquí no incluiremos los análisis acerca de las desigualdades generacionales, aunque sostenemos que es importante vincularlos a los enfoques desde las diversidades.

5 Abordamos el análisis de la juvenilización de la sociedad y la vida en los últimos años en Vommaro (2015 y 2015a) relacionándolos con los procesos de feminización. 
promoción de los consumos, los trabajos de expertos y académicos y las enunciaciones y prácticas de los propios colectivos juveniles. En un trabajo reciente Vázquez (2015) enfatizó la importancia de abordar los procesos de producción socioestatal de las juventudes desde una perspectiva relacional que pondere el valor de mostrar las tramas de actores, definiciones y situaciones (sociales, políticas, culturales, institucionales, subjetivas) en las que las juventudes son producidas en el presente (Vázquez, 2015: 6).

De esta manera, la pluralización del término remite no solo a que hay muchas maneras de ser, estar y presentarse joven, sino que además las formas de producir estas categorías son múltiples y variadas. Estos dispositivos constituyen expresiones de las modalidades de gobierno de las poblaciones, en clave de modulación social juvenil, en la actualidad. Así, las juventudes producen prácticas y lenguajes, se producen a sí mismas como parte de una acción subjetivante y son producidas a través de dispositivos socioestatales.

Diversos autores como Bourdieu (1990[1978]) y Lenoir (2000) han trabajado las modalidades específicas mediante las que son producidos los grupos o clases de edad (Martín Criado, 1998), enfatizando en los dispositivos sociales y estatales a partir de los cuales aquellas se despliegan.

Advertir estos procesos nos permite estar atentos a las dimensiones estadocéntricas y adultocéntricas (Duarte, 2002) de las modalidades de producción de las juventudes. En efecto, autores como Guattari advierten que

La juventud es algo que pasa en la cabeza de los adultos. Algo que existe en diferentes planos en el adulto, que existe como fantasma oculto, como práctica de segregación social, como atributo colectivo [...] pero en el fondo, la adolescencia, la realidad vivida, es algo que no puede determinarse como una clase de edad. Yo preferiría hablar de devenir. Devenir niño, devenir mujer, devenir sexo. Y este devenir puede empezar en cualquier momento de la existencia. No tiene por qué hacerlo necesariamente a los 15 o a los 28 años. Es posible convertirse en un niño, eso no es ninguna novedad, a los 75 años. Y también es posible no llegar a serlo nunca. Es posible chochear a los doce años, y es posible devenir mujer, planta o cualquier otra cosa, sin que nada de eso tenga relación alguna con la programación genética (Guattari, 1980).

Lo dicho hasta aquí nos permite enfatizar nuestro abordaje de las juventudes como noción dinámica, sociohistórica y culturalmente construida, siempre situada y relacional. 
Pensamos entonces, junto con otros autores, que la juventud es una noción dinámica, sociohistórica y culturalmente construida, que es siempre situada y relacional. En este sentido, autoras como Chaves (2006) y Alvarado, Martínez y Muñoz Gaviria (2009) señalan las dimensiones témporo-espaciales que configuran el proceso de producción de las juventudes. Proponen así que esta es una noción que cobra significado únicamente cuando la enmarcamos en el tiempo y en el espacio, es decir, cuando se reconoce como categoría situada en el mundo social en tanto cronotopo.

Este modo de abordaje de las juventudes nos permite realizar dos desplazamientos que consideramos importantes. Por un lado, alejarnos de la concepción de las juventudes solo en clave etaria, sociodemográfica o biológica. Parafraseando a Bourdieu (2005) y a Margulis y Urresti (1996) podemos decir que las juventudes son mucho más que un grupo de edad.

Por el otro, superar el enfoque de las juventudes desde la moratoria o suspensión vital. En efecto, por muchos años se analizaron las juventudes desde el aplazamiento, la cesantía y la moratoria, como un tiempo de espera, intermedio, en donde había cuestiones aún no resueltas que solo se saldarían con el paso a la adultez (Coleman y Husen, 1989; Keniston, 1970; Erikson, 1968; González y Caicedo, 1995). Las insuficiencias de estos postulados -- que Balardini calificó como "no lugar entre la infancia y la adultez" (Balardini, 2000: 10) - han sido ya demostradas por numerosos autores (Balardini, 2000; Margulis y Urresti, 1996; Pérez Islas, 2000, Chaves, 2006). Coincidimos entonces con Redondo (2000) en que la de juventudes es una noción "escurridiza”, pero en cualquier caso mucho más sociohistórica que biológica (Redondo, 2000: 180).

Avanzando con nuestra perspectiva de abordaje de las juventudes, proponemos reactualizar la noción de generación. Ya en 1928 Mannheim sostuvo que la generación no puede ser considerada como una mera cohorte, puesto que la sola contemporaneidad cronológica no es suficiente para definirla (Mannheim, I993 [1928]). Por el contrario, la idea de generación, antes que a la coincidencia en la época de nacimiento, "remite a la historia, al momento histórico en el que se ha sido socializado" (Margulis y Urresti, 1996: 26). Sin embargo, pensamos que una generación tampoco puede comprenderse solo a partir de la coexistencia en un tiempo histórico común, sino que para ser tal debe poner en juego de una u otra forma maneras de identificación común entre sujetos que comparten experiencias vitales situadas.

De ese modo, siguiendo a Lewkowicz, el vínculo generacional se constituye como efecto de un proceso de subjetivación ligado con una vivencia común en torno 
a una experiencia de ruptura a partir de la cual se crean mecanismos de identificación y reconocimiento en tanto parte constitutiva de un nosotros (Lewkowicz, 2004). Este autor propone definir una generación no como aquello ligado directamente a la edad de los individuos, sino como una producción social y subjetiva que se configura al experimentar problemas en común. Estos se expresan en una experiencia alteradora y, en ese sentido, las generaciones se caracterizan también por sus movimientos de ruptura:

una generación se constituye cuando el patrimonio legado se disuelve ante el embate de las circunstancias. Un saber transmitido se revela insolvente. Tenemos un problema: de esto no se sabe. Si nos constituimos subjetivamente como agentes de lo problemático del problema, advenimos como generación (Lewkowicz, 2004).

Así, una generación emerge a partir de una experiencia originaria, que podríamos vincular con la noción de acontecimiento en Badiou (2000), como punto en el que se constituye una nueva sensibilidad, un adoptar un lugar activo en una escena o coyuntura.

El abordaje generacional permite asumir el proceso histórico en el que, como lo señala Bauman (2007), las generaciones pueden sucederse, pero también superponerse, entramarse. De esta manera, el conflicto intergeneracional se expresa en las dinámicas políticas, sociales y culturales de las sociedades en las que se producen. Además, en un mismo momento histórico pueden coexistir - muchas veces en tensión- diferentes maneras de producir juventudes y de ser joven (Ghiardo, 2004: 44).

Este modo de abordar las juventudes desde la perspectiva generacional permite alejarse de la idea de que puedan ser asociadas - en tanto parte del ciclo de vida - con una predisposición específica hacia la política; ya sea hacia una mayor participación juvenil, como hacia la retracción de su compromiso político. Nos alejamos así de las posturas que remarcan tanto la apatía y el desinterés como el compromiso y la rebeldía en tanto rasgos inherentes o esenciales de las juventudes actuales. Seguimos en este punto a Urresti, quien postula que para interpretar a los jóvenes en un momento histórico singular es preciso "más que pedirles o juzgarlos por aquello que hacen o no hacen respecto de los jóvenes de generaciones anteriores, comprenderlos en su relación con la situación histórica y social que les toca vivir" (2000: 178).

Así, la consideración de los jóvenes como generación nos permite aprehender un conjunto de relaciones sociales y políticas en las cuales estos se encuentran 
inmersos, que los producen y modulan, así como también los procesos sociohistóricos que constituyen la dinámica del cambio social y en la cual ellos despliegan sus prácticas y producciones. Hablar de generación implica incluir el contexto de socialización - más amplio - en el cual una determinada cohorte se apropia, y al mismo tiempo resignifica y tensiona, las prácticas sociales y políticas del mundo en el que habita. Es este proceso de apropiación y modificación - este hacerse un lugar de las juventudes - lo que posibilita la ruptura y la innovación características de muchas experiencias políticas juveniles.

\section{Los procesos de politización}

Para abordar las complejas y múltiples relaciones que se construyen entre juventudes y políticas creemos necesario analizar brevemente las transformaciones que experimentó la política en los últimos 30 años y explorar la diversidad de prácticas, formas organizativas $y$ asociativas, construcciones identitarias y culturales y modalidades de subjetivación política que produjeron los jóvenes en sus experiencias de participación y compromiso.

Los lugares y las formas de la política encuentran diversos modos de expresarse y resolverse, por ejemplo, las instituciones político-estatales y representativas, así como los colectivos sociales, en tanto agrupaciones que, tensionando la institucionalidad estatal, persiguen objetivos públicos y construyen modos distintos de disputar hegemonía (Tapia, 2008). Estos son la expresión de la "política salvaje" que propone Tapia (2008), una política no instituida y consagrada, muchas veces desacreditada, que desborda el terreno de la política legitimada — del sistema político- y avanza hacia la emergencia de otras formas que actualizan tradiciones y experiencias.

Desde estas propuestas coincidimos con Jelin en que lo político no es un a priori o una esencia. Al contrario, diferentes contenidos (incluso algunos considerados tradicionalmente privados o íntimos) pueden asumir un carácter público y confrontativo y así politizarse (Jelin, 1989). Asimismo, sostenemos que algunas prácticas culturales juveniles - aun cuando no han sido concebidas como políticas por los actores que las protagonizan - pueden ser leídas como modos de expresión de politicidad, en tanto "modos de contestar al orden vigente y formas de insertarse socialmente" (Reguillo, 2000), o bien de intervenir en el espacio de "lo común" (Nuñez, 2013). Así, prácticas no consideradas políticas desde enfoques clásicos o aun por sus protagonistas, pueden politizarse - devenir políticas - al calor de su publicidad, su contenciosidad, su organización y su dimensión colectiva. 
Esto puede incluir prácticas estéticas, expresivas, comunicacionales y culturales - lo que nos lleva a hablar de la politización de los espacios culturales y también de la culturización y estetización de la política (Borelli, 20Io) - y también dimensiones afectivas y corporales. De hecho, la politización de los ámbitos cotidianos significa también el devenir político de relaciones afectivas, politizar las emociones. Así también, instituir una dinámica en la que los cuerpos adquieren un lugar fundamental ya no solo como medios o expresiones de la política, sino como territorios de politización, producidos por el propio devenir político. Emerge así la política con el cuerpo y desde el cuerpo, una política que en otros trabajos denominamos "de cuerpo presente" (Vommaro, 2010 y 2015) que desdobla en clave de resistencias las dinámicas biopolíticas contemporáneas.

A partir de lo dicho, pensamos que la noción de politización permite abordar las relaciones entre juventudes y políticas considerando el proceso de ampliación de fronteras de lo político que se produjo en la Argentina y en América Latina en los últimos 40 años. ${ }^{6}$ En efecto, la politización de las relaciones y los espacios cotidianos diluyó ciertas fronteras entre lo privado y lo público dando pie a un avance de lo público en tanto producción de lo común y territorio de la política. Desde esta mirada, abordamos la política como una producción relacional y dinámica, en proceso. Asimismo, enfocamos a los jóvenes protagonistas fundamentales de estas transformaciones de los modos de la política, con sus innovaciones y continuidades respecto a modalidades anteriores (Vommaro, 2010 y 2015).

Siguiendo estos planteamientos, y asumiendo el proceso de ampliación de las fronteras de la política, de politización, la reversibilidad entre las esferas pública y privada ${ }^{7}$ y las experiencias de participación juvenil que sustentan este artículo, podemos sostener no tanto que toda práctica humana es política, sino que puede politizarse, devenir política.

Si bien sostenemos que las formas de expresión, producción y práctica de la política pueden multiplicarse y que existen diferentes modos de intervenir en $y$ producir lo público, y partimos de que las configuraciones generacionales de la política exceden lo instituido y la política legitimada, también asumimos que es necesario precisar el proceso por el cual una práctica, una experiencia o un grupo

6 Si bien puede ser pertinente para nuestros planteamientos, por razones de espacio no abordaremos aquí las distinciones entre "lo político" y "la política" que realizan sugerentemente autores como Arendt (1996), Rancière (1996) o Mouffe (2007). Sin embargo, adelantamos que la noción de politización puede presentarse como bisagra o frontera difusa entre ambas esferas.

7 Trabajamos esto en textos anteriores como reversibilidad entre las esferas de la producción y la reproducción (Vommaro, 20IO). 
se politizan, es decir, adquieren carácter público, conflictivo, organizado y colectivo. En este sentido, proponemos que la politicidad, la dimensión política de una producción juvenil, es más una hipótesis, una apuesta, un devenir que un punto a asumir a priori. Pensamos entonces la politicidad también en términos de potencialidad política de una práctica o experiencia y esto incluye las acciones y propuestas estéticas, expresivas y culturales juveniles. Retomamos así las propuestas que formulamos en un trabajo anterior junto a Bonvilliani, Palermo y Vázquez (20I0) en el que sosteníamos que:

la politización es un potencial u horizonte constitutivo de cualquier vínculo social. Sin embargo, para atribuirle carácter político a un colectivo y a un sistema de prácticas sociales, consideramos que es preciso reconocer, al menos, cuatro aspectos: I) que se produzca a partir de la organización colectiva; 2) que tenga un grado de visibilidad pública (ya sea de un sujeto, de una acción o de una demanda);3) que reconozca un antagonista a partir del cual la organización adquiere el potencial político; 4) que se formule una demanda o reclamo que adquiera un carácter público y contencioso (Bonvilliani, Palermo, Vázquez y Vommaro, 2010).

\section{La emergencia del territorio}

Diversos análisis coinciden en que en las últimas décadas el espacio ha cobrado una inusitada relevancia en las dinámicas políticas, sobre todo si nos centramos en las experiencias de los movimientos y organizaciones sociales en un plano comunitario (Harvey, 2008; Davis, 2007; Santos, 2005; Santos, 200I). Asimismo, si integramos el análisis de las juventudes concebidas como generación y la política en tanto politización, emerge el espacio no ya como un dato geográfico o físico, sino como una producción social, como un lugar habitado y construido, un entramado de relaciones sociales donde los aspectos materiales se abigarran con las dimensiones simbólicas y subjetivas.

Entendemos este espacio como socialmente producido, habitado, configurado por prácticas y experiencias en clave de territorio. Comprender el espacio en clave territorial nos permite también indagar en los procesos de politización de las relaciones cotidianas generacionalmente configurados. Así, dimensiones afectivas, emocionales, afinidades diversas, corporalidades y modos de vínculo se politizan produciendo espacialidades diversas que devienen territorios. Emerge de 
esta manera la política como producción territorial y el territorio como producción política (Vommaro, 2015).

Según lo dicho, el proceso es doble y reversible. El territorio cobra relevancia en tanto expresa producciones simbólicas y subjetivas y estas producciones adquieren visibilidad al expresarse territorialmente.

Así, el territorio puede ser construido, reproducido y transformado en una relación recíproca que deviene en la producción de lo otro mediado por la espacialidad. En este sentido, el territorio también es productor, reproductor y modificador de diversas configuraciones políticas entre las que en este artículo destacamos la generacional. La importancia que la dimensión territorial ha cobrado en la producción de los modos de vida en la actualidad llevó a que algunos autores consideren que desde el siglo XIX las sociedades occidentales experimentaron un cambio sustancial transitando desde el reinado del plano temporal hacia la preponderancia de una dimensión espacial-territorial. Esto es, el mundo se experimenta menos en clave de extensidades en el tiempo que como intensidades espaciales que se entraman instituyendo una dinámica social que podemos caracterizar como situacional (Foucault, 1984; Soja, 20II).

Estas transformaciones desdobladas con fuerza en las últimas décadas como parte de una mutación del sistema capitalista de dimensiones más generales (Negri, 1980; Negri y Lazzarato, 200I; Castells, 1974) pusieron el foco en los procesos de espacialización de la política y su significación en tanto ámbito vivido, experienciado, inmediato, así como en tanto espacio social más amplio, abarcador y simbólico (Vommaro y Daza, 2016).

Consideramos entonces que los procesos de politización de la vida social abordados desde la perspectiva generacional producen una transformación en las relaciones entre la política y el espacio en el cual esta es producida. Así, se configura el referido proceso ambivalente de territorialización de la política y de politización del territorio (Vommaro, 2015). De esta manera, el territorio no es concebido solo desde su dimensión geográfica y física ni como una noción estática, de fijación o retraimiento, sino como un elemento simbólico y dinámico desde el cual se despliegan emergencias y devenires. Entonces, proponemos que complejicemos los procesos de territorialización y desterritorialización que señalan muchos autores contemporáneos (Deleuze y Guattari, 1995) con un tercer movimiento, el de reterritorialización. Este marca una dinámica de desplazamiento permanente en la que la producción territorial, en tanto resistencia y politización generacionales, es también fuga, sustracción, éxodo (Virno, 2005; Mezzadra, 200I). 
Sostenemos entonces que durante las últimas décadas tanto en la Argentina como en América Latina se desplegó un proceso de politización del espacio que territorializó las prácticas políticas. Esto puede ser interpretado desde las configuraciones generacionales que potenciaron su emergencia en coyunturas singulares, a la vez que desde una perspectiva diacrónica que contribuye a la comprensión integral de este despliegue. Si bien estos rasgos comenzaron a gestarse a finales de los años sesenta, es en los tempranos ochenta cuando se consolidan y emergen tramando la política territorialmente situada. En este sentido, postulamos que las formas políticas producidas por las juventudes en décadas posteriores están signadas por pervivencias que, actualizadas y reconfiguradas, contienen muchos de los principales rasgos de la politización espacial de aquel periodo (Vommaro y Daza, 20I6). Estos cambios fueron produciendo una dinámica de pliegues, despliegues y repliegues, a la vez que de divergencias, convergencias y emergencias territorialmente situadas que signaron los devenires de las experiencias de politización generacional en las últimas décadas.

\section{Experiencias de politización territorial y generacional en la Argentina}

En este apartado nos acercaremos a las formas territoriales de producción política en clave generacional a partir de tres experiencias de politización juvenil territorial desplegadas en la Argentina en las últimas dos décadas.

Las experiencias que presentaremos, si bien actuales, pueden ser analizadas como expresiones, ecos y emergencias producidas a partir de lo que Raúl Zibechi denominó "rebelión juvenil de los noventa" (Zibechi, 1997). En efecto, en esta década podemos observar la conformación de colectivos, formas organizativas, expresiones y presentaciones públicas que, aunque desencantadas con las modalidades conocidas y consagradas, no dejan de mostrar experiencias de politización territorial relevantes y alternativas en las cuales los jóvenes extendieron sus capacidades innovadoras. Asimismo, la potencia y los rasgos propositivos $-\mathrm{y}$ no solo reactivos- que expresaron los colectivos juveniles en la última década en América Latina, y luego de 20or en la Argentina en particular, llevaron a Ernesto Rodríguez (20I2) a hablar de los "nuevos movimientos juveniles" que signan la dinámica política y social en la mayoría de los países de la región.

En estos denominados nuevos movimientos juveniles, que desde nuestra perspectiva presentan innovaciones y emergencias que muchas veces actualizan 
elementos presentes en momentos anteriores, pueden identificarse dos dimensiones de politización que experimentan desplazamientos, cruces y conflictos. En primer lugar, las formas clásicas de organización, participación y compromiso público que se desplazan hacia otro tipo de espacios y prácticas, en los que no solo no se rechaza la política, sino que la politización se produce sobre la base de la impugnación de los mecanismos delegativos de participación y toma de decisiones. Este es el movimiento que marcó la politización generacional en los años ochenta, y más fuertemente noventa, en la Argentina (podríamos fecharlo en el periodo 1983-2002/3).

En segundo término, una trayectoria que marca una nueva parábola de recomposición de la política partidaria e institucional centrada en el Estado; un reencantamiento con lo público estatal y con las formas clásicas de participación política dentro del sistema político. Es decir, el surgimiento de organizaciones que, nombrándose o autopercibiéndose como juveniles, se constituyen desde o en diálogo fluido con el Estado y encuentran en las políticas públicas de ciertos gobiernos latinoamericanos espacios fértiles de acción y desarrollo de sus propuestas. Son grupos que en algunos casos están vinculados a juventudes partidarias y que la mayoría de las veces se presentan como base de apoyo de los gobiernos en cuyas políticas públicas o instituciones participan. Esta es la dinámica que marca el proceso de recomposición estatal que se produjo en la Argentina luego de 2003. Sin embargo, destacamos que este regreso de la política vinculada a los partidos y a los canales institucionales propuestos desde el Estado no será una réplica de momentos anteriores. Al contrario, se asentará sobre otras bases caracterizadas por tres nociones fundamentales que aquí tratamos: territorio, politización y espacio público o común (Vommaro, 2012 y 2015).

La década de los noventa del siglo pasado en la Argentina - que desde nuestro enfoque se extiende desde 1989 hasta 200I, marcada por el neoliberalismo- ${ }^{8}$ es un momento en el que podemos destacar al menos dos procesos que caracterizan las relaciones entre juventudes y políticas que aquí estudiamos. Por un lado, el ya señalado desencantamiento con las formas clásicas de la política expresadas en los partidos políticos, sindicatos y en las instituciones del sistema político en general. En segundo término, este alejamiento de la política institucional centrada en el Estado es acompañado por una expansión de espacios alternativos de producción política, en general vinculados al trabajo barrial — territorial—, a ámbitos sociales

8 A nivel institucional y político, estos son los años de los gobiernos de Carlos Menem, presidente de la Argentina entre 1989 y 1999, y Fernando de la Rua, quien gobernó desde 1999 hasta diciembre de 200I, cuando renunció en una coyuntura de rebelión popular, alta conflictividad social, deslegitimación política y crisis económica. 
o culturales y a dinámicas que buscan la horizontalidad, la autonomía y la participación directa, discutiendo la política estadocéntrica, la delegación y el verticalismo (Vommaro, 2010 y 2015).

En estas características de las formas políticas producidas en los años noventa por los jóvenes organizados en diversos colectivos territoriales pueden rastrearse continuidades respecto de las maneras en las que se desplegó la politización generacional y territorial en la década anterior. Así, aquí proponemos una interpretación que busca visibilizar las pervivencias y actualizaciones más que resaltar las supuestas novedades o discontinuidades en las modalidades de producción de las configuraciones generacionales de la política.

De esta manera, discutimos con algunas interpretaciones que sostienen que lo característico de la década de los ochenta en la Argentina era la participación juvenil en partidos políticos, sindicatos y centros de estudiantes como espacios legítimos y valorados de inscripción de las prácticas político-ciudadanas, mientras en la década de los noventa estas formas organizativas mostraron serios límites para contener a las juventudes y expresar la formas de militancia política en general (Sidicaro y TentiFanfani, 1998).

A partir de las investigaciones que sustentan este trabajo podemos identificar que la lógica de politización en el territorio que se consolida en los años noventa expresa continuidades con las formas territoriales y comunitarias que identificamos para los años ochenta (Vommaro, 2010 y 2015; Vommaro y Daza, 2016). Así, modalidades anteriores se reconfiguran potenciando una producción política que tiende más a la participación que a la representación, a la acción directa que a las mediaciones institucionales, a politizar afectos y relaciones cotidianas cambiantes que a acuerdos ideológicos fijos y cristalizados (Zibechi, 2003: 50 y ss.). En otros trabajos denominamos esta lógica como político-social centrada en los procesos societales y sostuvimos que convive en el territorio con la dinámica político-partidaria basada en dimensiones estadocéntricas (Vommaro, 2012 y 2015).

\section{Los Movimientos de Trabajadores Desocupados como espacio de politización generacional}

En este proceso de consolidación de las configuraciones políticas territoriales y comunitarias con protagonismo generacional, la búsqueda de la autonomía aparece como elemento distintivo. Esta autonomía como horizonte de construcción política en tanto no dependencia de partidos políticos, sindicatos o iglesias y no reproducción 
de sus dinámicas de funcionamiento, se potencia con el desarrollo de experiencias de autogestión que visibilizan la dimensión productiva del territorio. Para acercarnos a experiencias que permitan profundizar lo anteriormente expuesto presentaremos algunas experiencias de los jóvenes organizados en el Movimiento de Trabajadores Desocupados (MTD) del barrio de San Francisco Solano, en Quilmes, al sur del Conurbano bonaerense.

Este movimiento surgió en 1997, aunque su génesis puede rastrearse en las formas de organización comunitaria y territorial que tuvieron lugar desde I98I y se consolidaron en las tomas y los asentamientos que analizamos en otros trabajos (Vommaro, 20IO). Al acercarnos a las características de los jóvenes que participan en el MTD de Solano estamos distanciándonos, además, de los estudios que enfocan a los jóvenes de los barrios pobres del Gran Buenos Aires desde las categorías de exclusión, desafiliación, vulnerabilidad y marginación y los conciben sin capacidades, condenados a la fragilidad y la supervivencia.

Si bien la experiencia de participación, organización y producción de los jóvenes en el MTD de Solano se produjo en una situación marcada por la pobreza, las desigualdades sociales y el desempleo que se agudizaron a causa de las políticas neoliberales predominantes en la Argentina en los años noventa, en nuestro trabajo de campo pudimos descubrir que hay jóvenes que, aun en estos escenarios, son capaces de construir organizaciones sociales con propuestas alternativas en lo productivo, lo político y lo subjetivo. Es decir, protagonistas de procesos instituyentes, afirmativos, disruptivos e innovadores de politización del espacio y producción en el territorio.

Podemos avanzar ahora en la interpretación de algunos rasgos característicos de las formas políticas que produjeron los jóvenes que se organizaron en el MTD de Solano en la segunda mitad de la década del noventa en la Argentina.

\section{Darío y Maxi}

Para hablar de los jóvenes en el MTD de Solano es oportuno comenzar por analizar las figuras de Darío Santillán y Maximiliano Kosteki que fueron adoptadas como símbolos de la militancia en las organizaciones de trabajadores desocupados - no sólo entre los jóvenes, aunque sobre todo entre ellos- luego de su asesinato en junio de 2002.

Darío Santillán y Maximiliano Kosteki —Darío y Maxi, como los nombraban sus compañeros - fueron asesinados por las fuerzas de seguridad en la represión a una manifestación e intento de corte del Puente Pueyrredón, el 26 de junio de 2002, durante la presidencia de Eduardo Duhalde. Darío tenía 2I años y Maxi 22 
cuando los mataron. Los episodios que rodearon su muerte se conocieron con el nombre de Masacre de Avellaneda.

Ambos se convirtieron en símbolos y referentes de la militancia territorial, denominada para algunos piquetera. Por ejemplo, el MTD de Guernica, donde militaba Maxi, pasó a llamarse Maximiliano Kosteki luego de la Masacre de Avellaneda. En 2004 surgió el Frente Popular Darío Santillán, que agrupó a varias organizaciones de desocupados - y también de otro tipo-, especialmente de la zona sur del Conurbano bonaerense y en La Plata. Por otra parte, en septiembre de 2009 nació la Coordinadora de Colectivos Maximiliano Kosteki, que agrupó a organizaciones territoriales que años atrás se autodenominaban como de trabajadores desocupados y que luego de 200I consolidan sus trabajos situados en el territorio. Entre las organizaciones que integraban esta Coordinadora estaba el MT d de Solano.

Dos caracterizaciones pueden servirnos para comprender el tipo de recuperación de las figuras de jóvenes como Darío y Maxi que se produjo entre los Movimientos de Trabajadores Desocupados, incluido el mTd de Solano. Por un lado, el Frente Popular Darío Santillán (FPDS) decía, desde su sitio web que Darío:

fue y es un referente muy importante y sintetiza los valores humanos y la conciencia política de las jóvenes generaciones que, desde un compromiso concreto con las reivindicaciones más urgentes de nuestro pueblo, luchan con vocación de impulsar cambios revolucionarios (FPDS, ¿Qué es el Frente Popular Darío Santillán?, 2007).

Por su parte, la Coordinadora de Colectivos Maximiliano Kosteki expresaba en la "Semblanza de Maxi" que:

Maximiliano Kosteki era un joven de 22 años que estudiaba el secundario con orientación artística para ingresar a la Facultad de Bellas Artes. Había realizado un curso de escultura y estudiaba pintura, dibujo y piano. También participó de un taller literario en Lomas de Zamora que actualmente lleva su nombre. Vendía flores, cuidaba perros y trabajaba en lo que se presentaba, pero siempre dibujaba, pintaba y escribía. Además hacía malabares, capoeira, tocaba el bajo, la flauta dulce y la armónica. El I ${ }^{\circ}$ de mayo de 2002 participó de su primera manifestación en Plaza de Mayo [...] Ese día conoció los proyectos del Movimiento de Trabajadores Desocupados (MTD) de Guernica: mantener un comedor, cuidar una huerta, una biblioteca, una panadería, etc. Comenzó a ir a las reuniones y participar en las actividades hasta que llegó su primer y último corte de ruta. Dos semanas antes del 26 de junio había expuesto 20 de sus obras y la noche anterior escribió: "miro mucho más de lo visible". El 26 de 
junio de $2002[\ldots]$ las fuerzas policiales realizaron una gran represión [...] persiguen a dos jóvenes desarmados en la estación de tren de Avellaneda y los asesinan a sangre fría. Ellos son Maximiliano Kosteki y Darío Santillán. Hoy día sus vidas y sus nombres son retomados por diversas organizaciones como señal de que la muerte no pudo parar el impulso creador de estos jóvenes (Colectivos Maximiliano Kosteki. Semblanza de Maxi, 2009).

Vemos en estos dos textos que se recupera una imagen de estos jóvenes vinculada tanto a los valores, la conciencia política y el compromiso militante - en el primer caso-, como a las cuestiones de la vida cotidiana, el acercamiento casi casual a la militancia, la expresión artística, los afectos, la participación política desde lo barrial y concreto, y el impulso creador, en el segundo. Esta recuperación está despojada de conflictos y contradicciones, alimentando una memoria vinculada a resaltar más los procesos de politización territorial desde lo cotidiano que los contrastes y tensiones propios de estas experiencias.

En este punto podemos incluir un elemento que contribuye a la fundamentación de nuestra perspectiva de abordar las configuraciones políticas a nivel generacional con base en el trabajo con colectivos juveniles territoriales en el mediano plazo. Nos referimos a las relaciones simbólicas que se establecieron en el MтD Solano entre estos jóvenes asesinados en 2002 y Agustín Ramírez, un joven del barrio impulsor de la organización territorial en la zona en los primeros años ochenta, luego de las tomas y los asentamientos que allí se produjeron y que fue asesinado en junio de I988 por la policía provincial.

Esta relación se expresó, por ejemplo, en la realización de un mural pintado en la esquina de la calle 89i en el barrio San Martín - a pocos metros del galpón que servía como sede del MTD de Solano en esa demarcación-, en que aparecían las caras de Darío y Agustín y, abajo, las fechas de sus asesinatos. Es decir, las luchas del barrio estaban encarnadas por jóvenes que desplegaron su militancia territorial allí mismo o en zonas cercanas y fueron asesinados por la policía a raíz de su participación política. La configuración generacional que tendía puentes y de alguna manera igualaba experiencias separadas por más de diez años se nutría tanto de la militancia situada, anclada en procesos cotidianos, como en haber sido muertos por fuerzas policiales. Estos elementos cimentaban la intención multiplicadora de la memoria actualizada y manifestada en el territorio.

La politización generacional en el MTD de Solano se produjo sobre todo en cuatro ámbitos. En primer lugar, en tres instancias vinculadas al trabajo territorial y las prácticas cotidianas. Estas son: los espacios de formación, los talleres productivos 
y los grupos de reflexión. En segundo lugar, en la ocupación de los espacios públicos que se produjo con los cortes de calle y la toma de edificios o plazas. En otros trabajos abordamos los sentidos políticos y subjetivos generacionalmente configurados de estas ocupaciones (Vommaro, 2015). Nos concentraremos aquí en los tres ámbitos ligados a la militancia territorial enfocando, por razones de espacio, solo en los talleres productivos como expresión de los procesos autogestivos y de producción en el territorio.

\section{Los talleres productivos}

Los talleres productivos eran uno de los espacios más importantes dentro del proyecto del mTd de Solano. No solo por su profundo contenido político y subjetivo, sino también porque desde allí se instituyeron formas productivas que mostraron posibilidades alternativas a la lógica capitalista de la ganancia y la explotación. Dentro de las lógicas productivas que se busca instituir a través de estos espacios podemos incluir a los talleres de formación y educación popular que también funcionaban con base en prácticas horizontales, estimulando la participación directa y la autogestión.

Entre los talleres productivos que funcionaban en el movimiento destacamos: panadería, trabajo en cuero, herrería, albañilería, granjas y huertas comunitarias. En cada uno de ellos se ponían en juego elementos vinculados a lo que Marx denominó general intellect o inteligencia colectiva y la afectividad comunitaria. Además, estos eran espacios autogestionados, en donde el proceso de trabajo era autoorganizado por los propios productores, tendiendo a derribar las jerarquías y divisiones propias del proceso de trabajo capitalista. Aparecían entonces las posibilidades de autoafirmación a partir de la autovaloración del trabajo.

Por otra parte, los talleres productivos constituían instancias de encuentro intergeneracional. En efecto, a diferencia de los otros ámbitos analizados en este apartado, los talleres productivos no eran exclusivamente protagonizados por los jóvenes, y en algunos casos estos eran minoría. Sin embargo, la impronta alternativa e innovadora estaba dada muchas veces por el componente juvenil.

Cuando nos referimos a estos talleres como espacios de encuentro intergeneracional pensamos en dos dimensiones. Por un lado, muchos saberes productivos - vinculados a técnicas de trabajo y conocimientos específicos de la práctica laboral- eran aportados por los miembros de más edad de la organización (entre los 40 y los 50 años, o más), aquellos que habían transitado por el mundo del trabajo 
- más o menos formal, más o menos fabril-y habían aprendido técnicas profesionales de las que los más jóvenes carecían. Esto era especialmente notorio en talleres como el de herrería o el de albañilería.

Por otro, los más jóvenes carecían de esos conocimientos y técnicas, pero estaban embarcados en la búsqueda de nuevos modos de organizar el trabajo y la producción. La experiencia de los adultos se convertía en este punto en un elemento ambiguo. Por una parte, ellos brindaban las técnicas de trabajo necesarias para poner en marcha el proceso productivo. Por la otra, las formas de organizar el proceso de trabajo - por ejemplo, los tiempos, el ritmo-y las relaciones laborales que encarnaban eran las que habían aprendido y estaban relacionadas con los modos dominantes, la reproducción de jerarquías y la explotación, y eso no era lo que el MTD se proponía generar en estos espacios.

Así, mientras los adultos aportaban muchos conocimientos y técnicas de trabajo, los más jóvenes confrontaban los modos de organización del proceso laboral que aquellos habían aprendido, y buscaban instituir otra lógica productiva basada en la cooperación, la afectividad y la producción de lo común. Desde luego, este encuentro generacional no estuvo exento de conflictos y contradicciones. Muchas de las discusiones en los talleres se produjeron por las diferencias que mencionamos antes. Además, la disolución —en muchos casos temporal— de algunos talleres en ciertos barrios también estuvo vinculada —además de con dificultades económicas relacionadas con la compra de insumos o maquinarias - con los conflictos políticos y subjetivos planteados en esta confluencia intergeneracional.

\section{Politización juvenil en la recomposición estatal}

Como dijimos, en los años noventa el barrio se consolidó como una de las principales unidades territoriales de organización popular desde donde emanaron las acciones colectivas de protesta en contra de los gobiernos denominados neoliberales o neoconservadores. Este hecho favoreció la consolidación de redes sociales territoriales que entramaron sujetos diversos igualados por la experiencia de crisis general y sus estrategias colectivas en esa coyuntura. En este contexto los modos de ser y actuar de las juventudes se tornaron relevantes en tanto promotores de espacios alternativos de producción política que implicaron también modos diversos de entender y habitar las espacialidades singularizadas.

Muchas prácticas comunitarias resultaron potentes en términos de creatividad, solidaridad y resistencia, lo que señalaría una década marcada por la 
autoorganización diversificada de modalidades de apropiación de la acción política directa en clave espacial-comunitaria.

Luego de la denominada crisis de 200 que se vivió en la Argentina en parte como eclosión de los procesos de politización territorial de la década de los noventa, las nuevas generaciones de jóvenes se agruparon en torno a procesos anclados en ese pasado inmediato y en otro más lejano que otorgaron sentido a la acción grupal generacional territorializada. Esto fue notorio en la zona de Quilmes en la que realizamos nuestro trabajo de campo. Así, el foco de la participación política en los colectivos juveniles que emergieron al calor y luego de los procesos de movilización que surgieron con la crisis fue el trabajo en y con las comunidades, que potenció los procesos territoriales. Así, la politización generacional vigorizó sus rasgos territoriales expresados en una diversidad de espacios y prácticas. Las dimensiones estética, expresiva, afectiva, comunicativa y cultural cobraron protagonismo en tanto capacidades de organizar voluntades políticas para construir espacios comunes a partir del reconocimiento de las diversidades que caracterizan los territorios.

De esta manera, podemos identificar al menos tres ámbitos de participación y movilización juveniles en este periodo: la estudiantil, con los procesos de ocupación de escuelas secundarias en la ciudad de Buenos Aires y algunas provincias desde 2006; la de las juventudes partidarias, entre las que se destacan las denominadas juventudes $\mathrm{K}$, pero donde también hay otros grupos; $y$ la de los colectivos territoriales y culturales, que mantienen y actualizan sus formas de organización en los barrios, conectados muchas veces con el Estado a través de algunas políticas públicas, además de las ya conocidas formas de represión abierta y cotidiana que experimentan. En estas tres vertientes se manifiestan y dirimen los procesos de disputas por el uso, apropiación y producción de lo público (en tanto producción del espacio común) que señalamos en este trabajo.

Aquí presentaremos una experiencia vinculada con las configuraciones generacionales de la política a nivel territorial y otra enmarcada en las juventudes partidarias que regresan su mirada al Estado y las políticas públicas como espacios de despliegue de sus prácticas.

\section{Hagamos lo imposible}

Podemos analizar la politización territorial que emerge luego de la crisis de 200I, en el marco del proceso de recomposición estatal, a partir de la experiencia del denominado Frente de Organizaciones en Lucha (FOL). Este Frente se crea en febrero 
de 2006 con la intención de aunar en un mismo espacio múltiples agrupamientos con finalidades sociopolíticas similares, priorizando la participación de trabajadores precarizados, estudiantes, jóvenes y desocupados en un ámbito común que excediera e integrara las organizaciones preexistentes.

Dicho frente reivindica la democracia y la acción directa como herramientas principales para alcanzar sus objetivos enmarcados en algunos principios más clásicos como la conciencia política, la lucha social y la emancipación de la clase obrera mediante la construcción de medios comunitarios y la puesta en marcha de herramientas estético colectivas dirigidas a niños, jóvenes y adultos de la comunidad. "Hagamos lo imposible" (HLI) es una de las organizaciones juveniles que integran el frente. Esta agrupación juvenil buscó, desde que fue constituida en Quilmes, en 2009, generar en las comunidades barriales procesos de construcción de conocimientos críticos mediante acciones con fuerte énfasis pedagógico y comunicacional. $\mathrm{Al}$ igual que en el FoL, los jóvenes organizados en HLI lograron entablar estrechos vínculos tanto afectivos como estratégicos con las comunidades en las que llevan a cabo sus proyectos.

Los procesos de producción y reproducción de memoria desempeñan un papel importante en estas agrupaciones para la construcción cotidiana de sus apuestas políticas. Tanto el FOL como HLI tienen entre sus referentes inmediatos de movilización colectiva experiencias comunitarias de luchas anteriores en la zona, tal como las acontecidas en los procesos de tomas de tierras y construcción de asentamientos de los años ochenta. ${ }^{9}$ Como ya referimos, luego de estas acciones, en 1988 , fue asesinado el joven líder comunitario Agustín Ramírez, a manos de la policía, junto a su compañero de militancia, Javier Sotelo. Tanto la figura de Agustín como la de otros jóvenes militantes también asesinados por la policía en el marco de sus prácticas políticas — como Darío Santillán o Maximiliano Kosteki, cuyas experiencias ya analizamos - son representadas en murales y materiales que producen estos movimientos. Esto nos permite interpretar las experiencias de politización comunitaria y territorial también a partir de lo que podríamos denominar la construcción de una memoria territorial que incide activamente en los procesos de politización

9 Entre agosto y diciembre de I98I se produjeron en la zona de San Francisco Solano (municipios de Quilmes y Almirante Brown, sur del Gran Buenos Aires) tomas de tierras y construcción de asentamientos que dieron lugar a la emergencia de seis barrios: La Paz, Santa Rosa, Santa Lucía, El Tala, San Martín y Monte de los Curas (actual Barrio 2 de abril). En este proceso, que significó la ocupación de unas $2 \mathrm{II}$ hectáreas, participaron alrededor de 4600 familias, es decir unas 20000 personas aproximadamente (Vommaro, 2009a y 2010). El protagonismo juvenil, enmarcado generalmente en las Comunidades Eclesiales de Base (сев) fue uno de los rasgos característicos de esta experiencia. 
territorializada tanto de las organizaciones como de las comunidades en las que estas operan.

Un texto publicado en su sitio web en el que HLI elabora una autodefinición de la organización para darse a conocer ante otros jóvenes puede expresar la diversidad de espacios, prácticas y sentidos que se despliegan en los territorios y confluyen en este colectivo.

Somos un Frente de jóvenes que, desde distintas especificidades, trabajamos todos los días para construir una alternativa. Como talleristas barriales y educadores populares, vamos a los barrios a socializar nuestros conocimientos, a poner en diálogo nuestros saberes con los de los propios vecinos, para enseñar y aprender, para construir colectivamente un conocimiento crítico que nos ayude a vivir mejor, que nos ayude a organizarnos mejor para así enfrentar con más herramientas los problemas que la sociedad actual genera. Como artistas fomentamos y construimos centros culturales, para aportar a un circuito alternativo de producción, distribución y exposición artística, que sea propio de los trabajadores de la cultura; construimos centros culturales que a su vez sean centros sociales. Como comunicadores fomentamos el desarrollo de medios comunitarios, alternativos y populares, que en el ejercicio de la contrainformación se basen en los intereses populares. Como estudiantes impulsamos espacios de organización participativos y democráticos al interior de nuestros espacios de estudio, que devuelvan el protagonismo y la iniciativa a los propios estudiantes; porque los estudiantes no estamos aislados ni por fuera de esta realidad dolorosa que siempre nos atraviesa ("Un poco de historia", texto publicado en $<$ http://hagamosloimposible.com/un-poco-de-historia/ $>$ ).

En este texto elaborado por el propio colectivo juvenil puede verse cómo se presentan desde dimensiones y espacios múltiples. Ante todo se constituyen como jóvenes (la juventud como elemento de autoadscripción, autoafirmación y causa pública que vimos más arriba). También despliegan sus proyectos en tanto talleristas barriales, educadores, artistas, comunicadores, estudiantes. Es decir, gestan una producción de lo común no unívoca ni homogeneizadora, hacen posible lo común en la diversidad que entrama política, educación, arte, comunicación y constituye una de las configuraciones singulares de la politización generacional territorial en la actualidad. 


\section{La Cámpora}

Por otra parte, durante el gobierno de Néstor Kirchner (2003-2007) se emprendieron algunas acciones que es conviene señalar y que delinearán ciertas rupturas en relación con lo acontecido desde su asunción. Una de las primeras marcas de su gestión fue el proceso de reconstitución de la autoridad presidencial y de la legitimidad de la política institucional. En ello tuvo sin duda un fuerte peso la política de derechos humanos, el cambio en la composición de la Corte Suprema de Justicia, la retórica en torno a la dignidad nacional y la convocatoria a romper con el modelo económico neoliberal y los vínculos con los organismos internacionales de crédito.

Una de las cuestiones nodales que caracterizaron este momento fue el debate sobre las modalidades y los espacios que fue adquiriendo la participación política de las juventudes en el contexto de particulares formas del ejercicio del liderazgo político. En este sentido, creemos que existen numerosos indicios que nos permiten plantear un crecimiento de la participación juvenil en estructuras caracterizadas como clásicas. Es decir, en los ámbitos instituidos de participación consagrados por las democracias liberales, como los partidos y los sindicatos.

A partir de lo dicho, no obstante, nos distanciamos de las ideas que señalan que estas fueran las únicas formas políticas existentes durante estos años. Como dijimos, podemos constatar una mayor participación de las juventudes en los espacios institucionales. Pero esto no significa que las formas de participación vinculadas a espacios autónomos, territorializados y alternativos hayan desaparecido ni que la participación de las juventudes en estructuras partidarias sean las únicas legitimadas o visibles en el espacio público. Podemos sostener que conviven las dos modalidades, se entretejen, se solapan, entran en tensiones y se transforman mutuamente. En una palabra, más que en remplazos, proponemos pensar en superposiciones, pliegues, cruces y actualizaciones de formas anteriores.

Para centrarnos en los procesos de politización generacional que analizamos aquí y explicar la parábola de recomposición de la política partidaria e institucional centrada en el Estado que mencionamos al comienzo de esta sección, presentaremos ahora el caso de las agrupaciones juveniles kirchneristas, cuya importancia señalan tanto trabajos académicos como periodísticos. Esta experiencia nos permite, además, hablar de la emergencia de una militancia juvenil con presencia en todo el país que apoya al partido en el gobierno. Es posible sostener que ello no se veía en la Argentina desde el retorno democrático de 1983. Por otra parte, como lo afirmamos en un trabajo anterior, esto es parte de un proceso más general, ya que durante los años de los gobiernos kirchneristas se produjeron cambios sustantivos 
en las formas de movilización y en las experiencias organizativas de buena parte de los movimientos sociales y políticos de la Argentina, lo cual fue particularmente visible entre las organizaciones juveniles (Vázquez y Vommaro, 20I2).

Independientemente de las posiciones asumidas inicialmente hacia la presidencia de Néstor Kirchner, los espacios militantes existentes atravesaron inflexiones en cuanto a sus estrategias organizativas que redundaron en el apoyo más o menos directo a ese gobierno. Asimismo, en este periodo se crearon agrupaciones que adoptaron una posición oficialista, orientando su capacidad organizativa a apoyar al gobierno kirchnerista interpretado como parte de un proyecto o modelo con el que tenían significativos acuerdos. En este segundo grupo de organizaciones es posible identificar muchas agrupaciones juveniles kirchneristas. Entre ellas, La Cámpora fue la más visible. ${ }^{10}$ Una primera aproximación a este grupo nos lleva a preguntarnos por la manera en que se elabora un relato sobre el origen del colectivo que conjuga elementos resignificados y actualizados del pasado con hechos recientes, en el marco de los cuales se explicita el nacimiento de la agrupación. Podemos comenzar reflexionando sobre el nombre de la agrupación, alusivo a la figura de Héctor Cámpora, ${ }^{11}$ y la manera en que se construye una lectura acerca del peronismo que permite reinterpretarlo desde el presente, aspirando a desarrollar un conjunto de prácticas que se sitúan en una relación de continuidad con gobiernos peronistas de los años cuarenta, cincuenta y setenta. Estas interpretaciones acerca del peronismo, por otra parte, condensan sentidos heterogéneos y recuperan figuras de diferentes momentos que recorren el primer peronismo, la resistencia y el peronismo del siglo XxI, salteando los años menemistas (1989-1999), que no son reconocidos en esta genealogía militante como peronistas, sino como "neoliberales" (Vázquez y Vommaro, 2012).

Así, la construcción de un relato que permita comprender e interpretar la génesis de este y otros grupos autodefinidos como kirchneristas fue parte de un mismo esfuerzo por explicitar el surgimiento del kirchnerismo y cimentar su legitimidad (Vázquez y Vommaro, 20I2). Un elemento llamativo en la producción de este relato

10 Para ampliar sobre La Cámpora y otras organizaciones juveniles kirchneristas véase Vázquez y Vommaro (2012).

11 Héctor José Cámpora (1909-1980) fue electo presidente de la Argentina el II de marzo de 1973 y asumió el cargo el 25 de mayo de ese año. La fórmula que conformó, junto con Solano Lima, permitió el regreso del peronismo al gobierno en una época en la que Perón permanecía proscrito. La gestión duró 49 días, ya que Cámpora renunció para posibilitar la realización de nuevas elecciones en las que se presentó como candidato Juan Domingo Perón. Era conocido como el Tío y se caracterizó por expresar al sector de la izquierda peronista y por sintetizar, desde el punto de vista de los militantes, la lealtad a Perón bajo cualquier circunstancia. 
es que, si bien la gran mayoría de dirigentes de estas agrupaciones comenzaron sus experiencias de politización en los ya referidos años noventa, ya fuera en centros estudiantiles universitarios, secundarios o en organizaciones barriales o territoriales, la imagen construida sobre esa época es de apatía y despolitización. Más allá del objetivo instrumental de generar un contraste entre los años menemistas y la ya mencionada repolitización basada en la recomposición estatal posterior a 2003, no deja de ser significativa esta construcción de sentido. Como ya señalamos, no podríamos entender los acontecimientos de diciembre de 2001 y comienzos de 2002 sin tomar en cuenta las experiencias de politización, organización y movilización que se produjeron en los años noventa, durante la larga década neoliberal en la Argentina, en los cuales muchos colectivos juveniles emergieron como expresión de la política territorial y comunitaria.

Por otra parte, tanto La Cámpora como varias de las denominadas agrupaciones kirchneristas (la Juventud Peronista Evita, por ejemplo), son organizaciones que se autodefinen como juveniles. Esta apelación a lo juvenil era utilizada como una forma de referir a un modo de práctica política que se caracterizaba como novedoso. De esta manera, los conflictos políticos aparecen expresados en clave de disputa generacional, contraponiendo la joven militancia con las estructuras caracterizadas como tradicionales, sobre todo del Partido Justicialista, pero también del sistema político en general. Ser joven se convierte entonces en un valor político positivo, que simboliza una tensión o contradicción con las formas de hacer política o gestionar el Estado consideradas viejas.

En tercer lugar, es posible identificar otra manera de apelar a la idea de juventud, que se observa desde los dirigentes que integran el mundo adulto de la política. La juventud es invocada a partir de la caracterización de la coyuntura en la que desde el punto de vista adulto - les toca vivir a los más jóvenes. Para los dirigentes adultos del kirchnerismo, el contexto se presentaba como una oportunidad, puesto que, desde su punto de vista, existen mejores condiciones para militar que aquellas a las que se enfrentaban quienes fueron jóvenes en los setenta. Esta centralidad de la juventud entre los dirigentes se observaba no solo en las convocatorias a los jóvenes sino, además, en la inclusión de una agenda política que los contenga. Esto se reconoce, por ejemplo, en el impulso que cobraron las diferentes políticas públicas orientadas a la juventud durante los gobiernos kirchneristas (Vázquez, 2013 y 2015).

Asimismo, todo esto estuvo acompañado por la apertura de espacios políticos para los jóvenes. En este sentido, la militancia de esos años incluyó asumir responsabilidades legislativas o de gestión en el Estado. Eentre los militantes de muchas agrupaciones kirchneristas aparecieron términos como militar una ley, militar una 
política — pública - o militar una campaña. Se otorgaron así atributos militantes a estos espacios en la función pública que serían similares u homologables, desde el punto de vista de los jóvenes kirchneristas, a los que organizan el trabajo en un barrio (Vázquez, 2013 y 2015).

Podemos identificar entonces dos formas en las que se presentaba la relación entre la militancia juvenil kirchnerista, en particular de La Cámpora, y el Estado. Por un lado, una militancia desde el Estado, encarnada por los miembros de la agrupación que además de ser militantes se desempeñan laboralmente en dependencias estatales de diverso tipo. En esta situación se encontraban desde aquellos que ocupaban cargos de gestión y se reivindicaban públicamente como activistas de La Cámpora, hasta las personas que trabajaban en el Estado con anterioridad y que - producto de la vinculación con La Cámpora - resignificaron su desempeño y sus funciones laborales allí. Por otro, una militancia para el Estado o por el Estado, utilizada para hacer referencia a las circunstancias en las que sus militantes se definen como activadores de las políticas públicas desarrollando prácticas que denominan bajar planes y programas sociales en diferentes barrios o comunas. Es importante señalar que esto contrasta con la concepción de la política que prevalecía en algunos colectivos de militantes juveniles en los años noventa - que podemos caracterizar como una militancia en paralelo o contra el Estado-, en muchos de los cuales se politizaron los dirigentes de La Cámpora. Así, en el kirchnerismo el Estado era visto como una posible herramienta de transformación y un espacio de disputas políticas que era preciso ocupar y al que había que dedicarle esfuerzo y tiempo militante.

Recapitulando, podemos identificar al menos cuatro sentidos diferentes en cuanto a las configuraciones generacionales que se expresaron en agrupaciones juveniles kirchneristas como La Cámpora. El primero es el referido a la juventud como forma de autodefinición o autoidentificación. El segundo se vincula con la manera de simbolizar conflictos entre generaciones, por medio de la cual se homologa lo joven con lo nuevo y se restablece un modo de entender la política que se contrapone al tradicional, asociado a los viejos dirigentes. En tercer lugar, la juventud se presenta como una apelación realizada desde la dirigencia adulta, en particular desde sus dos principales referentes: Cristina y Néstor. Finalmente, en el marco del ya referido proceso más amplio de juvenilización de la sociedad y la política, por medio del cual se entiende la exaltación de rasgos juveniles como atributos positivos de los militantes, lo que incluso lleva a destacar estas características entre dirigentes adultos que procuran juvenilizarse. 


\section{Reflexiones finales}

En este artículo pudimos explorar experiencias de politización juvenil territorial desde una perspectiva diacrónica, poniendo en relación dos procesos que se desplegaron en momentos distintos en una misma zona (Quilmes, sur del Gran Buenos Aires, Argentina) con un caso de organización política juvenil enmarcada en la recomposición estatal producida luego de 2003 y vinculada entonces a la acción de un gobierno y sus políticas públicas.

Las múltiples relaciones establecidas entre las dos experiencias desplegadas en Quilmes (el MTD de Solano y HLI), con sus continuidades y rupturas, que incluso pueden rastrearse en los años ochenta, permiten identificar tres elementos que nos interesa destacar. Por un lado, la construcción de una memoria territorial de la zona de Quilmes que posibilita trazar líneas de continuidad entre experiencias de politización de momentos distintos, con rasgos que se actualizan en cada coyuntura al calor de cambios generacionales. Así, los modos de expresar las prácticas políticas situadas se configuran también desde redes sociales comunitarias constituidas a partir de afinidades y afectos inscritos en el territorio. Esto produce espacios públicos en tanto expresión de lo común en la diferencia que son disputados al calor de los procesos de politización generacionales e instituyen marcas corporales persistentes.

De esta manera, en segundo lugar, la política territorial que estudiamos no solo tensiona lo público en tanto brecha entre los vínculos ciudadanos estadocéntricos y las relaciones mercantiles desiguales al instituir espacios comunitarios (Vommaro, 2015), también es una política de cuerpo presente, donde las corporalidades constituyen el territorio de la politización. Así, los cuerpos devienen en producciones políticas. En efecto, producir política desde y con el cuerpo y los afectos es uno de los rasgos de las configuraciones generacionales que nos proponemos comprender.

Como tercer punto, identificamos una parábola en los procesos de politización territorializados en la Argentina luego de la situación abierta por la crisis de 200I. Este movimiento resitúa la política en términos estatales al permitir una recomposición de la capacidad del Estado para implementar políticas públicas. Sin embargo, este reencantamiento con lo público estatal no replica modalidades anteriores. La política como producción territorial, el territorio como producción política, el despliegue de la politización en espacios comunitarios y los procesos de disputa por lo público son marcas generacionales que llegaron para quedarse y se expresan no solo en los colectivos que podemos caracterizar como territoriales, sino también en las organizaciones juveniles vinculadas a espacios partidarios y gobiernos. 
Como cuestión a pensar en futuros trabajos se plantea analizar si este desplazamiento en los procesos de politización generacionales hacia espacios estatales vinculados a las políticas públicas se produjo también en otros países de América Latina. Algo dijimos en trabajos anteriores acerca de la expresión de este proceso en Chile y Brasil (Vommaro, 2015). Sería interesante reflexionar en este sentido acerca de la actual coyuntura colombiana. En efecto, el movimiento que converge en torno a la consigna \#PazALaCalle, gestado luego del resultado del plebiscito del 2 de octubre de 20I6, puede ser una expresión de una dimensión de la politización juvenil que resitúa su acción en el marco de las políticas públicas. Si bien el proceso de Colombia nos muestra la persistencia de un Estado neoliberal, con muchos rasgos neoconservadores y un resquebrajamiento de la legitimidad de los mecanismos de representación política y las mediaciones estatales, el escenario abierto por el proceso de paz podría producir desplazamientos en las politizaciones generacionales cuya dinámica se dirimirá en los avatares del proceso político y los desafíos del fin del enfrentamiento armado.

Otra dimensión que no consideramos suficientemente en este artículo y deberá ser abordada en otros textos es la de género. En efecto, la politización territorial y generacional se produce también a partir de dinámicas de género que fundamentan un necesario cruce entre ambas perspectivas.

A partir de las tres experiencias aquí estudiadas nos acercamos a la identificación de algunas de las principales características que distinguen las configuraciones generacionales de la política en la actualidad. Así, pudimos indagar en las continuidades y rupturas que actualizan los procesos de politización juvenil territorialmente situados poniendo en relación agrupaciones que emergen desde los territorios con otras surgidas al calor del proceso político abierto con la recomposición del Estado en la inflexión kirchnerista. Resulta claro entonces que, más allá de quiebres y disrupciones, las marcas de la politización generacional territorializada son persistentes y definen buena parte de la dinámica política y social en la actualidad de la Argentina y la región.

\title{
Referencias bibliográficas
}

\author{
Aguirre Baztan, A. (ed.) (1995), Etnografía. Metodologíacualitativaenlainvestiga- \\ ción sociocultural, Madrid, Boixareu.
}


Alvarado, Sara V., Jorge. E. Martínez y Diego Muñoz Gaviria (2009), "Contextualización teórica al tema de las juventudes: una mirada desde las ciencias sociales de la juventud", Revista Latinoamericana de Ciencias Sociales, Niñez y juventud, 7(I), pp. 83-102.

Arendt, Hannah (1997), ¿Qué es la política?, Barcelona, Paidós.

Bertaux, David (2005), Los relatos de vida. Perspectivas etnosociológicas, Barcelona, Bellaterra.

Badiou, Alain (2000), Movimiento social y representación politica, Buenos Aires, Instituto de Estudios y Formación de la CTA.

Balardini, Sergio (2000), Prólogo en Sergio Balardini (comp.), La participación social y política de los jóvenes en el horizonte del Nuevo Siglo, Buenos Aires, Clacso, pp. 7-I9.

Bauman, Zygmund (2007), "Between Us, the Generations”, en J. Larrosa (ed.), On generations. On coexistence between generations, Barcelona, Fund. Vivir y Convivir, pp. 365-376.

Bonvillani, Andrea, Alicia Palermo, Melina Vázquez y Pablo Vommaro (2010), "Del Cordobazo al kirchnerismo. Una lectura crítica acerca de los períodos, temáticas y perspectivas en los estudios sobre juventudes y participación política en la Argentina”, en S. Alvarado y P. Vommaro (eds.), Jóvenes, cultura y política en América Latina: algunos trayectos de sus relaciones, experiencias y lecturas (1960-2000), Buenos Aires, CLACsoHomo Sapiens, pp. 2I-54.

Borelli, Silvia (2010), “'Qué significa investigar en juventud?”, conferencia dictada en el Posdoctorado en Ciencias sociales, Niñez y Juventud, Buenos Aires.

Bourdieu, Pierre (1990[1978]), "La «juventud» no es más que una palabra” en $P$. Bourdieu, Sociología y cultura, México, Grijalbo, pp. 163-173.

Castells, Manuel (1974), La cuestión urbana, Madrid, Siglo XXI Editores.

Colectivos Maximiliano Kosteki (2009), Semblanza de Maxi, Buenos Aires.

Coleman, J. S. y T. Husen (1989), Informe ocDE: inserción de los jóvenes en una sociedad de cambio, Madrid, Narcea.

Chaves, Mariana (2006), "Investigaciones sobre juventudes en Argentina: estado del arte en ciencias sociales 1983-2006", Papeles de trabajo, 5, Buenos Aires, Idaes-Universidad Nacional de San Martín.

Davis, Mike (2007), "Los suburbios de las ciudades del tercer mundo son el nuevo escenario estratégico decisivo", en Rebelión, enero. 
Deleuze, Gilles y Felix Guattari (1995), Conversaciones 1972-199o, Valencia, Pre-Textos.

Duarte, Klaudio (2002), "Mundos jóvenes, mundos adultos: lo generacional y la reconstrucción de los puentes rotos en el liceo. Una mirada desde la convivencia escolar", en Última década, I6, pp. 99-II8.

Erikson, Erik (1968), Identidad: juventud y crisis, Madrid, Taurus.

Foucault, Michel (1984), "Of OtherSpaces, Heterotopias" en Architecture, Mouvement, Continuité, 5, octubre, pp. 46-49.

Frente Popular Darío Santillán (FPDS) (2007), ¿Qué es el Frente Popular Darío Santillán?, La Plata.

Geertz, Clifford (1993), La interpretación de las culturas, Barcelona, Gedisa.

Ghiardo, Félix (2004),"Generaciones y juventud: una relectura desde Mannheim y Ortega y Gasset”, Última década, 20, junio, pp. II-46.

González, G. y M. Caicedo (1995), "La intervención social en las subculturas juveniles urbanas en Latinoamérica", ponencia presentada en el Precongreso del V Congreso Nacional de Pedagogía Lasallista, Medellín.

Guattari, Félix (1980),"Viaje a la adolescencia”, El Viejo Topo, 43, abril, pp. 47-50. Guber, Rosana (200I), La etnografía. Método, campo y reflexividad, Buenos Aires, Norma.

Hammersley, M. y P. Atkinson (1994), Etnografía, Buenos Aires, Paidós. Harvey, David (2008), "El derecho a la ciudad", New LeftReview, 53, noviembre-diciembre, pp. 23-39.

HLI (20I6), "Un poco de historia”, en <http://hagamosloimposible.com/un-poco-de-historia/> [consulta: $18 / 10 / 2016]$.

Jelin, Elizabeth (comp.) (1989), Los nuevos movimientos sociales, Buenos Aires, CEAL.

Joutard, Philip (1986), Esasvocesquenosllegan del pasado. México, Fondo de Cultura Económica.

Keniston, K. (1970),"Youth a New Stage of Life", en The American Scholar, 2(37). Kornblit, Ana Lía (coord.) (2004), Metodologías cualitativas en ciencias sociales. Modelos y procedimientos, Buenos Aires, Biblos.

Lenoir, Remi (2000) "Savoirs et sciences d'État: généalogie et démographie", Actes de la recherche en sciences sociales, I33, pp. 96-97.

Lewkowicz, Ignacio (2004), “La generación perdida”, El Signo, 7 de abril.

Mannheim, Karl (1993[1928]),"El problema de las generaciones", Revista Española de investigación sociológica, 62, pp. 193-242. 
Margulis, Mario y Marcelo Urresti (1996), "La juventud es más que una palabra” en M. Margulis (ed.), La juventud es más que una palabra. Ensayos sobre cultura y juventud, Buenos Aires, Biblos.

Martín Criado, Enrique (1998), Producir la juventud, Madrid, Istmo.

Mezzadra, Sandro (200I), Diritto di fuga, Verona, Ombre Corte.

Mouffe, Chantal (2007), En torno a lo político, Buenos Aires, FCE.

Necoechea, Gerardo y Pablo Pozzi (2008), Cuéntame cómo fue. Introducción a la Historia oral, Buenos Aires, Imago Mundi.

Negri, Antonio (10980), Del obrero masa al obrero social, Barcelona, Anagrama. Negri, Antonio y Maurizio Lazzarato (200I), Trabajo inmaterial. Formas de vida $y$ producción de la multitud, Río de Janeiro, DP\&A.

Nuñez, Pedro (2013), La politica en la escuela, Buenos Aires, La Crujía.

Pérez Islas, José Antonio (coord.) (2000), "Visiones y versiones. Jóvenes, instituciones y políticas de juventud” en J. Martín-Barbero et al., Umbrales. Cambios culturales, desafios nacionales y juventud, Medellín, Corporación Región.

Portelli, Alessandro (1997), TheBattle of Valle Giulia. Oral History and the Art of Dialogue, Madison, TheUniversity of Wisconsin Press.

Rancière, Jacques (1996), El desacuerdo. Filosofía y política, Buenos Aires, Nueva Visión.

Redondo, Jesús (2000), "La condición juvenil: entre la educación y el empleo", Última década, 12, Viña del Mar, cipdA, pp. 175-223.

Reguillo, Rossana (2000), Emergencia de culturas juveniles. Estrategias del desencanto, Buenos Aires, Norma.

Rodríguez, Ernesto (2012), Movimientos juveniles en América Latina: entre la tradición y la innovación, Montevideo, celaju-unesco.

Santos, Boaventura de Sousa (200I), "Los nuevos movimientos sociales", OSAL, 5, septiembre.

Santos, Milton (2005), "O retorno do territorio", OSAL, 6(I6), junio, pp. 25I-26I.

Sidicaro, Rircardo y Emilio TentiFanfani (1998), La Argentina de los jóvenes, Buenos Aires, Unicef Losada.

Soja, E. (20II), “Seeking Spatial Justice”, EURE, 37(III), pp. 173-177.

Tapia, Luis (2008), Politica salvaje. La Paz, Clacso-Muela del Diablo-Comunas. Vázquez, Melina (2013),"En torno a la construcción de la juventud como causa pública durante el kirchnerismo: principios de adhesión, participación y reconocimiento", Revista Argentina de Estudios de Juventud, I(7), pp. I-25. 
Vázquez, Melina y Pablo Vommaro (2012), "La fuerza de los jóvenes: aproximaciones a la militancia kirchnerista desde La Cámpora”, en G, Pérez y A. Natalucci (eds.), Vamos las bandas. Organizaciones y militancia kirchnerista, Buenos Aires, Trilce, pp. 149-174.

Virno, Paolo (2005), Ocurrencia y acción innovadora. Por una lógica del cambio, Buenos Aires, Tinta Limón.

Vommaro, Pablo (2010), Politica, territorio y comunidad: las organizaciones sociales urbanas en la zona sur del Gran Buenos Aires (1970-2000), tesis doctoral inédita, Facultad de Ciencias Sociales, Universidad de Buenos Aires.

Vommaro, Pablo (2012),“200I antes y después: la consolidación de la territorialidad", Forjando, I, julio, pp. Io6-II7.

Vommaro, Pablo (2015), Juventudes y políticas en la Argentina y en América Latina. Tendencias, conflictos y desafíos, Buenos Aires, Grupo Editor Universitario.

Vommaro, Pablo (2015a), entrevista en el Diario Página 12 (Argentina) “Hay una juvenilización de la sociedad” (3I/07/2015), en <http://www.paginar2. com.ar/diario/universidad/I0-27835I-2015-07-31.html $>$.

Vommaro, Pablo (2015b), "Movilizaciones juveniles en América Latina actual: hacia las configuraciones generacionales de la política", Revista Controversias y Concurrencias Latinoamericanas, 7(II), junio, pp. 25-54.

Vommaro, Pablo y Giovanny Daza (2016), “Jóvenes en territorio. Política y espacialidad colectiva en barrios del sur del Gran Buenos Aires entre los años ochenta y la actualidad", en Vázquez, Nuñez, Vommaro y Blanco. Militancias juveniles en la Argentina democrática. Trayectorias, espacios y figuras de activismo, Buenos Aires, Imago Mundi [en prensa].

Zibechi, Raúl (1997), La revuelta juvenil de los 9o: las redes sociales en la gestación de una cultura alternativa, Montevideo, Nordan.

Zibechi, Raúl (2003), Genealogía de la Revuelta. Argentina: sociedad en movimiento, Montevideo, Nordan.

Reseña CURRICULAR

Doctor en Ciencias Sociales por la Universidad de Buenos Aires. Profesor de Historia de la Universidad de Buenos Aires. Investigador del conicet. Co-coordina el Equipo de Estudios de Políticas y Juventudes (EPoJu, Instituto Gino Germani, uвA). Integrante del Grupo de Trabajo clacso "Juventudes e 
Infancias: políticas, culturas e instituciones sociales". Docente de la Facultad de Filosofía y Letras de la uвA en los Departamentos de Ciencias de la Educación e Historia y en el Posgrado. Publicaciones: Juventudes y políticas en la Argentina $y$ en América Latina. Tendencias, conflictos y desafíos. Grupo Editor Universitario, Buenos Aires, 2015; "La persistencia de la organización popular: algunas reflexiones en torno a las organizaciones sociales de base territorial y comunitaria en la Argentina contemporánea", en P. Forni y L. Castronuovo, Ni punteros ni piqueteros. Organizaciones populares durante el kirchnerismo, La Plata, EDULP, pp: 167-I88; "Movilizaciones juveniles en América Latina actual: hacia las configuraciones generacionales de la política", Revista Controversias y Concurrencias Latinoamericanas, 7(II), junio, pp. 25-54.

Citar como: Vommaro, Pablo Ariel (2017), "Territorios y resistencias: configuraciones generacionales y procesos de politización en Argentina", Iztapalapa. Revista de Ciencias Sociales y Humanidades, núm. 82, año 38, enero-junio de 20I7, ISSN: 2007-9176; pp. IOI-133. Disponible en <http://revistaiztapalapa.izt.uam.mx/index.php/izt/issue/archive $>$. 